\title{
Prediabetes among HIV-infected individuals receiving antiretroviral therapy: prevalence, diagnostic tests, and associated factors
}

\author{
Angsana Phuphuakrat ${ }^{1}$, Hataikarn Nimitphong ${ }^{1}$, Sirimon Reutrakul ${ }^{2}$ and Somnuek Sungkanuparph ${ }^{3 *}$
}

\begin{abstract}
Background: Metabolic complications in human immunodeficiency virus (HIV)-infected individuals are common. Prediabetes represents a high risk for future diabetes development. This study aimed to determine the prevalence, diagnostic methods, and associated factors of prediabetes among HIV-infected individuals receiving antiretroviral therapy (ART).
\end{abstract}

Methods: A cross-sectional study was conducted among HIV-infected adults without a history of diabetes who were receiving ART. Fasting plasma glucose (FPG), 2-hour plasma glucose (2-h PG) after a 75-g oral glucose tolerance test, and hemoglobin A1c (HbA1c) were assessed.

Results: A total of 397 patients with a mean age of $47.0 \pm 9.8$ years and $55.7 \%$ male, were studied. All received ART with undetectable plasma viral load. The mean duration of ART was $9.6 \pm 5.2$ years, and the mean CD4 cell count was $554 \pm 235$ cells $/ \mathrm{mm}^{3}$. Among the patients, 28 (7.1\%) had first-diagnosed diabetes, and 133 (33.5\%) patients had prediabetes. Glycemia estimation by FPG, 2-h PG, and HbA1c showed a prediabetes prevalence of $17.4 \%, 14.7 \%$, and $12.5 \%$, respectively. The kappa statistics for the agreement of FPG and 2-h PG, HbA1c and 2-h PG, and HbA1c and FPG were $0.317,0.429$, and 0.396 , respectively. In multivariate analysis, hypertension [odds ratio (OR) 3.38 ; $95 \%$ confidence interval $(C \mathrm{Cl}), 1.16-9.91 ; p=0.026)$, and triglycerides $>150 \mathrm{mg} / \mathrm{dL}(\mathrm{OR} 2.11 ; 95 \% \mathrm{Cl}, 1.01-4.44 ; p=0.047)$ were factors significantly associated with prediabetes.

Conclusions: Prediabetes among HIV-infected individuals receiving ART is common. The agreements of glycemia estimation methods are minimal to weak. HbA1c may underestimate prediabetes prevalence. Using FPG together with $\mathrm{HbA1c}$ increases the detection rate to approximately three-quarters of prediabetes patients. HIV-infected individuals who had hypertension and hypertriglyceridemia should be regularly assessed for prediabetes.

Trial registration ClinicalTrial.gov, NCT03545217. Registered 1 June 2018-Retrospectively registered, https://clinicaltr ials.gov/ct2/show/NCT03545217

Keywords: Antiretroviral therapy, Associated factors, Diagnostic test, HIV, Prediabetes, Prevalence

${ }^{*}$ Correspondence: somnuek.sun@mahidol.ac.th

${ }^{3}$ Chakri Naruebodindra Medical Institute, Faculty of Medicine

Ramathibodi Hospital, Mahidol University, 111 Moo 14, Bang Pla, Bang Phli, Samut Prakan 10540, Thailand

Full list of author information is available at the end of the article

\section{Background}

HIV infection is a major health problem worldwide, especially in low-to middle-income countries. The use of combination antiretroviral therapy (ART) has modified the natural history of HIV infection, leading to a significant reduction in morbidity and mortality. As the natural history of the disease is modified, non-communicable diseases are becoming recognized complications of HIV

(c) The Author(s) 2020. This article is licensed under a Creative Commons Attribution 4.0 International License, which permits use, sharing, adaptation, distribution and reproduction in any medium or format, as long as you give appropriate credit to the original author(s) and the source, provide a link to the Creative Commons licence, and indicate if changes were made. The images or other third party material in this article are included in the article's Creative Commons licence, unless indicated otherwise in a credit line to the material. If material is not included in the article's Creative Commons licence and your intended use is not permitted by statutory regulation or exceeds the permitted use, you will need to obtain permission directly from the copyright holder. To view a copy of this licence, visit http://creativeco mmons.org/licenses/by/4.0/. The Creative Commons Public Domain Dedication waiver (http://creativecommons.org/publicdomain/ zero/1.0/) applies to the data made available in this article, unless otherwise stated in a credit line to the data. 
infection, including insulin resistance, type 2 diabetes (DM), and dyslipidemia. A study in the United States revealed that the incidence and prevalence of $\mathrm{DM}$ in HIV-infected men with ART exposure was approximately four times greater than that of HIV-seronegative men [1]. While ART suppresses HIV replication, chronic inflammation and immune activation are still ongoing. These are known to increase the risk of metabolic and cardiovascular diseases [2,3]. Chronic systemic inflammation resulting in dysregulation of glucose and lipid trafficking, utilization, storage [4] and elevated inflammatory biomarker levels is linked to an increased incidence of DM among HIV-infected patients [5].

Prediabetes, a condition in which blood sugars are elevated but not yet meeting the criteria for DM, represents a high risk for future diabetes development. The conversion rate to DM varied among the different populations but was estimated to be between 5 and $11 \%$ yearly [6,7], and up to $70 \%$ of people with prediabetes will eventually develop DM [8]. People with prediabetes may have concomitant nephropathies, chronic kidney disease, neuropathies, diabetic retinopathy and macrovascular diseases that are traditionally considered to be complications of diabetes [9-14]. It is well established that diabetes can be prevented or delayed in prediabetes patients using medications such as metformin and/or intensive lifestyle interventions $[6,15,16]$. Caring for patients with prediabetes focused on prevention of the progression to diabetes and minimization of the potential consequences of prediabetes. Therefore, the detection of prediabetes in HIV-infected patients is crucial to identify those who need interventions to reduce future diabetes risk.

The information on prevalence, diagnostic methods, and predicting factors of prediabetes among HIVinfected patients receiving ART are, however, scanty [17]. Previous studies have shown the inaccuracy of hemoglobin A1c (HbA1c) in HIV-infected individuals [18, 19]. The objectives of this study were to determine the prevalence of prediabetes, the agreement of prediabetes diagnostic methods, and its associated factors among HIV-infected individuals receiving ART.

\section{Methods}

\section{Study design and participants}

A cross-sectional study was conducted among HIVinfected adults who received ART and had undetectable plasma viral load (HIV viral load $<40$ copies $/ \mathrm{mL}$ ), and followed up at an infectious disease clinic in a university hospital in Bangkok, Thailand. HIV-infected individuals who were receiving ART were consecutively recruited from September 2017 to April 2018. Patients with a history of previously diagnosed DM or using anti-diabetic therapy were excluded. Ethics approvals were obtained from the institutional review boards and informed consent was obtained from participants prior to enrollment. Patient's information including age, gender, family history of DM in first degree relatives, history of smoking (currently smoking and previous history of smoking), history of alcohol drinking (currently drinking and previous history of drinking), underlying diseases, duration of known HIV infection, ART regimens, duration of ART, CD4 cell counts, anti-hepatitis $\mathrm{C}$ virus (HCV) result, serum creatinine and estimated glomerular filtration rate (eGFR) were collected. Hemoglobin (Hb), hematocrit (Hct), and mean corpuscular volume (MCV) were extracted from complete blood count. Anemia was defined as $\mathrm{Hb} \mathrm{lev-}$ els $<12.0 \mathrm{~g} / \mathrm{dL}$ in women and $<13.5 \mathrm{~g} / \mathrm{dL}$ in men [20]. Hypertension, dyslipidemia, nonalcoholic fatty liver disease, cancer, cerebrovascular disease, coronary artery disease, and chronic kidney disease were categorized as "yes" if the participants had a documented diagnosis of these conditions or were taking medications. The participants were asked if they performed regular physical activity (continuous non-sedentary behavior for more than 10 min that resulted in an increased respiratory rate or heart rate), as well as the duration of sedentary behavior (sitting or reclining, but not include sleeping).

\section{Anthropometric measurements and laboratory analysis}

All anthropometric measurements and blood tests were performed after an overnight fast (8 to $10 \mathrm{~h}$ ). Each patient was clinically assessed for body weight, body mass index (BMI), neck circumference, waist circumference, and hip circumference. Weight was measured with participants wearing light clothing and no shoes. BMI was calculated as weight $(\mathrm{kg}) / \mathrm{height}^{2}\left(\mathrm{~m}^{2}\right)$. All circumferences were measured to the nearest $0.1 \mathrm{~cm}$ using a tape measure. Neck circumference was measured by placing the superior border of the tape measure just below the laryngeal prominence and applied perpendicular to the long axis of the neck. Waist circumference was determined at the umbilical level and hip circumference was measured over non-restrictive underwear at the level of the maximum extension of the buttocks posteriorly on a horizontal plane.

For biochemical parameters, after an overnight fast, a $75 \mathrm{~g}$ oral glucose tolerance test (OGTT) was performed. Blood samples were obtained at $0 \mathrm{~min}$ for fasting plasma glucose (FPG), HbA1c, lipid profiles, liver function tests, serum creatinine, and at $120 \mathrm{~min}$ for 2-hour plasma glucose (2-h PG). The HbAlc assay performed in this study has been certified by the National Glycohemoglobin Standardization Program. Patients were divided into three groups: normal, prediabetes and DM [21]. Prediabetes was defined as FPG between 100 and $125 \mathrm{mg} / \mathrm{dL}$, or 2-h PG between 140 and $199 \mathrm{mg} / \mathrm{dL}$ 
following a 75-g OGTT, or an HbA1c between 5.7\% and $<6.5 \%$ [21]. DM was defined as an FPG $\geq 126 \mathrm{mg} / \mathrm{dL}$, or a 2 -hr PG $\geq 200 \mathrm{mg} / \mathrm{dL}$ following a 75 -g OGTT, or a $\mathrm{HbA} 1 \mathrm{c} \geq 6.5 \%[21]$.

\section{Statistical analysis}

A comparison of categorical data was performed using Chi square or Fisher's exact test. The one-way analysis of variance (ANOVA) or Kruskal-Wallis test was used to compare continuous data between groups. Tukey post hoc test was used to find means that are significantly different from each other. Kappa agreement was computed to estimate the agreement among the three diagnostic definitions. Logistic regression was used to determine the factors associated with prediabetes. Variables that presented a $p$-value $<0.2$ from univariate logistic regression were considered in a multivariate logistic regression model. Odds ratio (OR) and its 95\% confidence interval (CI) were estimated. All statistical analyses were performed using the Stata statistical software version 15.1.

\section{Results}

\section{Patient characteristics}

A total of 397 HIV-infected patients with a mean age of $47.0 \pm 9.8$ years were recruited. Of all, 221 (55.7\%) patients were male. The mean duration of known HIV infection was $11.9 \pm 6.4$ years. All patients have received ART with a mean duration of $9.6 \pm 5.2$ years and had undetectable plasma viral load. The mean CD4 cell count was $554 \pm 235$ cells $/ \mathrm{mm}^{3}$. Most patients (77.3\%) were receiving non-nucleoside reverse transcriptase inhibitor (NNRTI) as the component of their current ART regimen. Anti-HCV was positive in 11 of 208 patients (5.3\%).

Patients were divided into three groups: normal, prediabetes and DM. Of the 397 patients, 133 (33.5\%) had prediabetes; 28 (7.1\%) had first-diagnosed DM, and the rest had normal glucose tolerance. Mean values of FPG: 2-h PG following a 75-g OGTT in patients with normal, prediabetes, and DM were 89.8 \pm 5.7 : $98.6 \pm 19.0,99.0 \pm 9.9$ : $130.1 \pm 30.3$, and $129.5 \pm 32.7: 248.2 \pm 54.9 \mathrm{mg} / \mathrm{dl}$, respectively. The mean HbA1c in the corresponding groups were $5.2 \pm 0.3 \%, 5.5 \pm 0.5 \%$, and $6.4 \pm 1.1 \%$, respectively.

Table 1 shows the baseline characteristics of patients in the three groups; normal, prediabetes, and diabetes. There was a significant difference in the mean age among groups. Patients who had normal glucose metabolism were younger than those who had prediabetes $(p<0.001)$ and those who has diabetes $(p=0.004)$. There was no significant difference in age between the prediabetes and diabetes groups $(p=0.628)$. Proportions of patients with hypertension and those with a family history of diabetes were also significantly different among groups $(p<0.001$, both). The lifestyle of the participants in each group, as collected from self-reported physical activity and hours of sedentary behavior, was not significantly different. The proportions of patients receiving NNRTI and protease inhibitor (PI) were not different among the three groups.

For anthropometric measurements, neck and waist circumferences were significantly different among groups. Patients who had normal glucose metabolism had lower neck circumference than those who had prediabetes $(p<0.001)$ and those who had diabetes $(p=0.002)$. There was no significant difference in neck circumference between prediabetes and diabetes groups $(p=0.434)$. Also, patients who had normal glucose metabolism had lower waist circumference than those who had prediabetes $(p=0.011)$ and those who had diabetes $(p=0.006)$. There was no significant difference in neck circumference between prediabetes and diabetes groups $(p=0.316)$.

For laboratory investigations, alanine transaminase, low-density lipoprotein (LDL)-cholesterol, total cholesterol/high-density lipoprotein (HDL)-cholesterol ratio, and triglycerides were significantly different among the three groups. Their levels were the greatest in the DM group and lowest in the normal group. Patients who had normal glucose metabolism had lower triglycerides than those who had prediabetes and those who had diabetes $(p<0.001$, both). There was no significant difference in triglycerides between prediabetes and diabetes groups $(p=0.605)$. eGFR was significantly different among groups. Patients who had normal glucose metabolism had higher eGFR than those who had prediabetes $(p=0.008)$ and those who had diabetes $(p=0.023)$. There was no significant difference in eGFR between prediabetes and diabetes groups $(p=0.602)$. There was no statistically significant difference among groups regarding $\mathrm{Hb}$, Hct, and MCV $(p>0.05$, all). Anti-HCV was previously performed in 208 of all patients. There was no statistically significant difference among groups $(p=0.138)$.

\section{Measure of agreement}

Of those with prediabetes who completed all FPG, 2-h PG, and HbA1C measurements $(n=129)$, eight cases (6.2\%) were determined by all three methods (Fig. 1). Eight cases (6.2\%) were determined by FPG and 2-h PG, 7 cases $(5.4 \%)$ were determined by 2 -h PG and $\mathrm{HbA} 1 \mathrm{c}$, and 10 cases $(7.8 \%)$ were determined by FPG and HbA1c. The diagnosis of prediabetes was determined by FPG alone in 40 cases (31.0\%), 2-h PG alone in 33 cases (25.6\%), and HbA1c alone in 23 cases (17.8\%).

Tables 2, 3 and 4 show analysis of the agreement between FPG and 2-h PG, HbA1c and 2-h PG, and HbA1c and FPG, respectively. Kappa coefficients showed $p<0.001$ in all pairs of the analysis. Kappa coefficient values were $0.317,0.429$, and 0.396 for the estimate of agreement between FPG and 2-h PG, HbA1c and 2-h 
Table 1 Baseline characteristics of 397 study patients

\begin{tabular}{|c|c|c|c|c|}
\hline Characteristics & Normal $(n=236)$ & Prediabetes $(n=133)$ & Diabetes $(n=28)$ & $P$-value \\
\hline Age, years, mean $\pm S D$ & $45.1 \pm 10.3$ & $49.4 \pm 8.6$ & $51.2 \pm 6.9$ & $<.001$ \\
\hline Male gender, number (\%) & $123(52.1)$ & $82(61.7)$ & $16(57.1)$ & 0.206 \\
\hline Family history of diabetes, number (\%) & $75(32.3)$ & $42(32.3)$ & $20(71.4)$ & $<0.001$ \\
\hline History of smoking, number (\%) & $75(31.9)$ & $54(41.5)$ & $11(39.3)$ & 0.169 \\
\hline History of alcohol drinking, number (\%) & $129(54.9)$ & $89(68.5)$ & $16(57.1)$ & 0.039 \\
\hline Regular physical activity, number (\%) & $193(82.8)$ & $112(84.9)$ & $23(82.1)$ & 0.867 \\
\hline Sedentary behavior, hours per day, median (IQR) & $5(3-8)$ & $5(2-8)$ & $4(2-6)$ & 0.340 \\
\hline \multicolumn{5}{|l|}{ Underlying diseases, number (\%) } \\
\hline Dyslipidemia & $59(25.1)$ & $47(35.6)$ & $11(39.3)$ & 0.054 \\
\hline Hypertension & $20(8.5)$ & $29(22.0)$ & $12(42.9)$ & $<0.001$ \\
\hline NAFLD & $3(1.3)$ & $7(5.3)$ & $1(3.6)$ & 0.071 \\
\hline Cancer & $4(1.7)$ & $2(1.5)$ & $2(7.1)$ & 0.170 \\
\hline Others* & $6(2.5)$ & $5(3.8)$ & $1(3.6)$ & 0.559 \\
\hline Duration of HIV infection, years, mean \pm SD & $11.4 \pm 6.6$ & $12.6 \pm 5.8$ & $12.9 \pm 6.7$ & 0.168 \\
\hline \multicolumn{5}{|l|}{ Type of ART regimen, number (\%) } \\
\hline NNRTI-containing & $187(79.6)$ & $94(70.7)$ & $20(71.4)$ & 0.284 \\
\hline Pl-containing & $43(18.3)$ & $33(24.8)$ & $8(28.6)$ & 0.097 \\
\hline Duration of ART, years, mean $\pm S D$ & $9.1 \pm 5.2$ & $10.4 \pm 5.1$ & $10.2 \pm 5.2$ & 0.079 \\
\hline CD4 cell counts, cells $/ \mathrm{mm}^{3}$, mean $\pm S D$ & $549 \pm 223$ & $555 \pm 247$ & $694 \pm 271$ & 0.629 \\
\hline Body weight, $\mathrm{kg}$, mean $\pm \mathrm{SD}$ & $60.6 \pm 13.0$ & $62.8 \pm 12.2$ & $65.3 \pm 10.4$ & 0.076 \\
\hline Body mass index, $\mathrm{kg} / \mathrm{m}^{2}$, mean $\pm \mathrm{SD}$ & $22.7 \pm 3.9$ & $23.4 \pm 3.9$ & $24.1 \pm 2.8$ & 0.080 \\
\hline Neck circumference, $\mathrm{cm}$, mean $\pm \mathrm{SD}$ & $33.6 \pm 3.6$ & $35.1 \pm 3.7$ & $36.0 \pm 3.7$ & $<0.001$ \\
\hline Waist circumference, $\mathrm{cm}$, mean $\pm S D$ & $81.2 \pm 9.9$ & $84.5 \pm 11.1$ & $87.6 \pm 7.1$ & $<0.001$ \\
\hline Hip circumference, $\mathrm{cm}$, mean \pm SD & $93.2 \pm 7.0$ & $94.7 \pm 9.5$ & $94.8 \pm 5.5$ & 0.178 \\
\hline Alkaline phosphatase, $\mathrm{U} / \mathrm{L}$, mean $\pm \mathrm{SD}$ & $94.6 \pm 33.8$ & $87.3 \pm 32.6$ & $92.6 \pm 34.2$ & 0.511 \\
\hline Aspartate transaminase, $\mathrm{U} / \mathrm{L}$, mean $\pm \mathrm{SD}$ & $32.4 \pm 24.6$ & $34.2 \pm 17.1$ & $38.7 \pm 16.4$ & 0.681 \\
\hline Alanine transaminase, $\mathrm{U} / \mathrm{L}$, mean $\pm \mathrm{SD}$ & $35.1 \pm 24.4$ & $42.6 \pm 34.8$ & $57.2 \pm 41.0$ & $<0.001$ \\
\hline Albumin, $g / L$, mean $\pm S D$ & $38.9 \pm 2.8$ & $38.2 \pm 5.5$ & $39.8 \pm 2.9$ & 0.485 \\
\hline Total cholesterol, mg/dL, mean \pm SD & $200 \pm 37$ & $202 \pm 48$ & $227 \pm 62$ & 0.006 \\
\hline $\mathrm{HDL}$-cholesterol, mg/dL, mean $\pm \mathrm{SD}$ & $51 \pm 14$ & $48 \pm 15$ & $45 \pm 9$ & 0.028 \\
\hline $\mathrm{LDL}$-cholesterol, mg/dL, mean $\pm \mathrm{SD}$ & $125 \pm 32$ & $123 \pm 38$ & $143 \pm 52$ & 0.032 \\
\hline Total cholesterol/HDL-cholesterol ratio, mean \pm SD & $4.1 \pm 1.2$ & $4.4 \pm 1.5$ & $5.1 \pm 1.5$ & $<0.001$ \\
\hline Triglycerides, mg/dL, mean $\pm S D$ & $125 \pm 81$ & $186 \pm 143$ & $208 \pm 122$ & $<0.001$ \\
\hline Serum creatinine, $\mathrm{mg} / \mathrm{dL}$, mean $\pm \mathrm{SD}$ & $0.8 \pm 0.2$ & $0.9 \pm 0.3$ & $0.9 \pm 0.2$ & 0.017 \\
\hline $\mathrm{eGFR}, \mathrm{mL} / \mathrm{min} / 1.73 \mathrm{~m}^{2}$, mean $\pm \mathrm{SD}$ & $97.6 \pm 17.6$ & $91.6 \pm 19.2$ & $87.9 \pm 17.9$ & 0.001 \\
\hline Hemoglobin, g/dL, mean \pm SD & $13.5 \pm 1.7$ & $13.9 \pm 1.8$ & $13.8 \pm 2.4$ & 0.104 \\
\hline Hematocrit, \%, mean \pm SD & $39.6 \pm 4.6$ & $40.7 \pm 5.0$ & $41.0 \pm 6.0$ & 0.057 \\
\hline Mean corpuscular volume (fL), mean $\pm S D$ & $89.4 \pm 12.9$ & $90.5 \pm 11.7$ & $87.1 \pm 12.8$ & 0.407 \\
\hline Anti-HCV positive, number $(\%)(n=208)$ & 4 of $128(3.1)$ & 6 of $64(9.4)$ & 1 of $16(6.3)$ & 0.138 \\
\hline
\end{tabular}

$\mathrm{ART}=$ antiretroviral therapy; eGFR = estimated glomerular filtration rate; $\mathrm{HCV}=$ hepatitis $\mathrm{C}$ virus; $\mathrm{HDL}=$ high-density lipoprotein; $\mathrm{LDL}=$ low-density lipoprotein; $\mathrm{NAFLD}=$ nonalcoholic fatty liver disease; NNRTI = non-nucleoside reverse transcriptase inhibitor; $\mathrm{PI}=$ protease inhibitor

*Including cerebrovascular disease, coronary artery disease and chronic kidney disease

Pairwise comparisons of the significant results by Tukey post hoc test

Age: normal vs. prediabetes $p<0.001$; normal vs. diabetes $p=0.004$; prediabetes vs. diabetes $p=0.628$

Neck circumference: normal vs. prediabetes $p<0.001$; normal vs. diabetes $p=0.002$; prediabetes vs. diabetes $p=0.434$

Waist circumference: normal vs. prediabetes $p=0.011$; normal vs. diabetes $p=0.006$; prediabetes vs. diabetes $p=0.316$

Alanine transaminase: normal vs. prediabetes $p=0.050$; normal vs. diabetes $p=0.001$; prediabetes vs. diabetes $p=0.048$

Total cholesterol: normal vs. prediabetes $p=0.924$; normal vs. diabetes $p=0.004$; prediabetes vs. diabetes $p=0.012$

HDL-cholesterol: normal vs. prediabetes $p=0.133$; normal vs. diabetes $p=0.070$; prediabetes vs. diabetes $p=0.492$

LDL-cholesterol: normal vs. prediabetes $p=0.846$; normal vs. diabetes $p=0.042$; prediabetes vs. diabetes $p=0.025$

Total cholesterol:/HDL-cholesterol: normal vs. prediabetes $p=0.052 ;$ normal vs. diabetes $p<0.001 ;$ prediabetes vs. diabetes $p=0.038$

Triglyceride: normal vs. prediabetes $p<0.001$; normal vs. diabetes $p<0.001$; prediabetes vs. diabetes $p=0.605$

Serum creatinine: normal vs. prediabetes $p=0.021$; normal vs. diabetes $p=0.289$; prediabetes vs. diabetes $p=0.999$

eGFR: normal vs. prediabetes $p=0.008$; normal vs. diabetes $p=0.023$; prediabetes vs. diabetes $p=0.602$ 


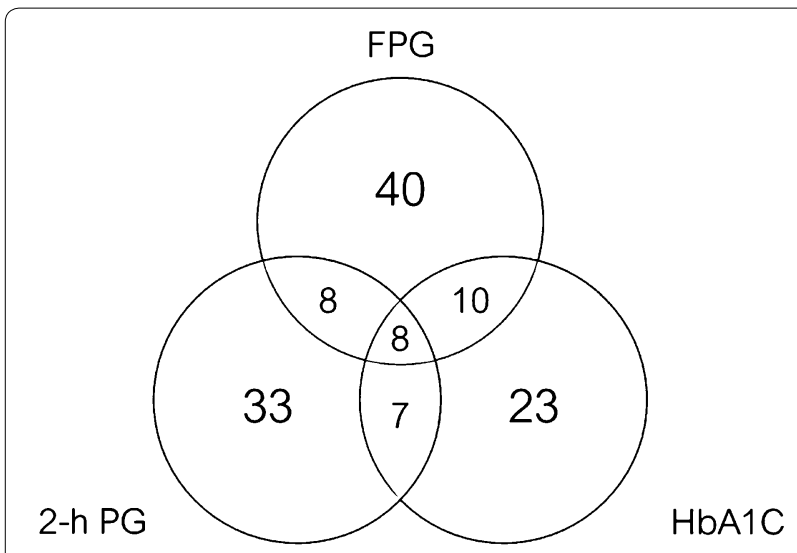

Fig. 1 Diagnosis of prediabetes in HIV-infected individuals using fasting plasma glucose (FPG), 2-hour plasma glucose (2-h PG) after performing $75-\mathrm{g}$ oral glucose tolerance test (OGTT), and hemoglobin $\mathrm{A} 1 \mathrm{c}(\mathrm{HbA1c})$

Table 2 Analysis of the agreement between fasting plasma glucose and 2-hour plasma glucose (2-h PG) after performing 75-g oral glucose tolerance test (OGTT)

\begin{tabular}{lcccc}
\hline & \multicolumn{2}{l}{$\mathbf{2 - h}$ PG } & & Total \\
\cline { 2 - 4 } & $<\mathbf{1 4 0}$ & $\mathbf{1 4 0 - 1 9 9}$ & $\mathbf{2 0 0}$ & \\
\hline FPG & 249 & 40 & 4 & 293 \\
$<100$ & 51 & 16 & 0 & 67 \\
$100-125$ & 0 & 0 & 21 & 21 \\
$\geq 126$ & 300 & 56 & 25 & 381 \\
Total & & & & \\
\hline
\end{tabular}

2-h PG 2-hour plasma glucose, $\mathrm{Cl}$ confidence interval, $F P G$ fasting plasma glucose Kappa coefficient $=0.317 ; 95 \% \mathrm{Cl} 0.241-0.376(P<0.001)$

Table 3 Analysis of the agreement between HbA1C and 2-hour plasma glucose (2-h PG) after performing 75-g oral glucose tolerance test (OGTT)

\begin{tabular}{lcccc}
\hline & \multicolumn{2}{l}{$\mathbf{2 - h}$ PG } & & Total \\
\cline { 2 - 4 } & $<\mathbf{1 4 0}$ & $\mathbf{1 4 0 - 1 9 9}$ & $\mathbf{2 0 0}$ & \\
\hline HbA1c & & & & \\
$<5.7$ & 263 & 41 & 0 & 304 \\
$5.7-6.4$ & 33 & 15 & 0 & 48 \\
$\geq 6.5$ & 0 & 0 & 25 & 25 \\
Total & 296 & 56 & 25 & 377 \\
\hline
\end{tabular}

2-h PG 2-hour plasma glucose, $\mathrm{Cl}$ confidence interval, HbA1c hemoglobin A1c Kappa coefficient $=0.429 ; 95 \% \mathrm{Cl} 0.360-0.519(P<0.001)$

PG, and HbA1c and FPG, respectively. After the exclusion of persons with anemia, $\mathrm{MCV}<80$ or $>100 \mathrm{fL}$, or eGFR $<60 \mathrm{~mL} / \mathrm{min} / 1.73 \mathrm{~m}^{2}$, kappa coefficients values were 0.438 and 0.299 for the estimate of agreement
Table 4 Analysis of the agreement between hemoglobin A1c and fasting plasma glucose

\begin{tabular}{lrrrr}
\hline & \multicolumn{2}{c}{ FPG } & & Total \\
\cline { 2 - 3 } & $<\mathbf{1 0 0}$ & $\mathbf{1 0 0 - 1 2 5}$ & $\mathbf{2 1 2 6}$ & \\
\hline HbA1c & & & & \\
$<5.7$ & 266 & 50 & 0 & 316 \\
$5.7-6.4$ & 31 & 18 & 0 & 49 \\
$\geq 6.5$ & 4 & 0 & 24 & 28 \\
Total & 301 & 68 & 24 & 393 \\
\hline
\end{tabular}

Cl confidence interval, FPG fasting plasma glucose, HbA1c hemoglobin A1c

Kappa coefficient $=0.396 ; 95 \% \mathrm{Cl} 0.356-0.411(P<0.001)$

between HbA1c and 2-h PG, and HbAlc and FPG, respectively.

\section{Factors associated with prediabetes}

When considering patients with prediabetes, univariate logistic regression was performed to investigate factors associated with prediabetes. On univariate logistic regression, age $>45$ years, alcohol drinking, hypertension, dyslipidemia, BMI $\geq 25 \mathrm{~kg} / \mathrm{m}^{2}$, neck circumference $>35 \mathrm{~cm}$, waist circumference $>85 \mathrm{~cm}$, alanine transaminase $>40$ $\mathrm{U} / \mathrm{L}, \quad \mathrm{HDL}$-cholesterol $<40 \mathrm{mg} / \mathrm{dL}$ and triglycerides $>150 \mathrm{mg} / \mathrm{dL}$, eGFR, $\mathrm{Hb}$, and positive anti-HCV were factors associated with prediabetes (Table 5). On multivariate logistic regression of factors associated with prediabetes, hypertension (OR 2.22; 95\% CI 1.16-9.91; $p=0.026)$, and triglycerides $>150 \mathrm{mg} / \mathrm{dL}$ (OR $1.98 ; 95 \%$ CI 1.01-4.44; $\mathrm{p}=0.047$ ) were factors significantly associated with prediabetes (Table 5).

\section{Discussion}

The current study examined the prevalence, agreement among diagnostic methods, and associated factors of prediabetes among HIV-infected individuals receiving ART in Thailand. The results revealed a strikingly high prevalence of prediabetes at $33.5 \%$. In addition, $7.1 \%$ of the study patients were found to have newly diagnosed DM, although FPG had been regularly monitored every 6 months in HIV-infected individuals at our clinic according to the national guidelines. The prevalence of prediabetes in this study appeared to be higher than the $10.6 \%$ rate in the general Thai population as revealed by the survey during the same period [22]. Our prevalence rates of prediabetes and DM are comparable to the results from a recent study among HIV-infected individuals in Cameroon (34\% with prediabetes and 3.8\% with DM) [23], and higher than those in many sub-Saharan African countries [24]. The rates are also higher than our previous study in Thailand in 2006 (impaired fasting glucose and impaired glucose tolerance test of $9.3 \%$ and 
Table 5 Univariate and multivariate analysis of factors associated with prediabetes

\begin{tabular}{|c|c|c|c|c|c|c|}
\hline \multirow[t]{2}{*}{ Factors } & \multicolumn{3}{|c|}{ Univariate analysis } & \multicolumn{3}{|c|}{ Multivariate analysis } \\
\hline & OR & $95 \% \mathrm{Cl}$ & $p$ value & OR & $95 \% \mathrm{Cl}$ & $p$ value \\
\hline Age $>45$ years old & 2.03 & $1.29-3.17$ & 0.002 & 1.89 & $0.84-4.25$ & 0.127 \\
\hline Alcohol drinking ${ }^{A}$ & 1.78 & $1.14-2.80$ & 0.012 & 1.44 & $0.68-3.04$ & 0.337 \\
\hline Hypertension & 3.03 & $1.63-5.61$ & $<0.001$ & 3.38 & $1.16-9.91$ & 0.026 \\
\hline Dyslipidemia & 1.65 & $1.04-2.62$ & 0.034 & 1.46 & $0.69-3.09$ & 0.327 \\
\hline Body mass index $\geq 25 \mathrm{~kg} / \mathrm{m}^{2}$ & 1.65 & $1.02-2.66$ & 0.041 & 1.06 & $0.39-2.88$ & 0.916 \\
\hline Neck circumference $>35 \mathrm{~cm}$ & 2.33 & $1.48-3.65$ & $<0.001$ & 1.34 & $0.52-3.48$ & 0.548 \\
\hline Waist circumference $>85 \mathrm{~cm}$ & 2.19 & $1.40-3.44$ & 0.001 & 0.93 & $0.33-2.60$ & 0.887 \\
\hline $\mathrm{ALT}>40 \mathrm{U} / \mathrm{L}$ & 1.79 & $1.13-2.84$ & 0.013 & 1.54 & $0.71-3.35$ & 0.273 \\
\hline $\mathrm{HDL}$ cholesterol $<40$ mg/dL & 1.64 & $1.00-2.70$ & 0.050 & 1.11 & $0.45-2.75$ & 0.814 \\
\hline Triglycerides $>150$ mg/dL & 2.72 & $1.74-4.26$ & $<0.001$ & 2.11 & $1.01-4.44$ & 0.047 \\
\hline eGFR & 0.98 & $0.97-0.99$ & 0.003 & 0.99 & $0.96-1.01$ & 0.183 \\
\hline Hemoglobin & 1.14 & $1.01-1.29$ & 0.037 & 0.98 & $0.79-1.22$ & 0.856 \\
\hline Positive anti-HCV & 3.21 & $0.87-11.80$ & 0.080 & 3.98 & $0.98-16.24$ & 0.054 \\
\hline
\end{tabular}

a Currently drinking or the previous history of drinking

$A L T$ alanine transaminase, $C l$ confidence interval, $e G D R$ estimated glomerular filtration rate, $H C V$ hepatitis $C$ virus, $H D L$ high-density lipoprotein, $O R$ odds ratio

$18.6 \%$, respectively) [17], and in 2009 (27.5\% determined by FPG and/or HbA1c) [25], suggesting that the rate of dysglycemia among HIV-infected individuals may be rising.

For the prediabetes diagnostic methods, we observed the interpretation varied throughout the three methods. Our results showed that FPG revealed the highest numbers, whereas $\mathrm{HbA1C}$ revealed the lowest numbers of prediabetes diagnosis. This was consistent with previous findings demonstrating lower sensitivity of $\mathrm{HbA} 1 \mathrm{C}$ compared to FPG in detecting prediabetes [26, 27]. Overall, the kappa coefficient values of each pairing were 0.3-0.5, which corresponded to minimal to weak agreement of each method [28]. This is similar to a large study in the general Thai population which revealed the kappa statistic for the agreement of FPG and 2 h-PG was 0.55 [29]. In HIV-infected patients, Coelho and coworkers demonstrated poor agreement of prediabetes and DM diagnostic methods [30] with HbA1c being the least sensitive method and OGTT being the most sensitive method. A previous study in non-diabetic persons showed different types of anemia influenced HbA1c differently [31]. Chronic kidney disease (CKD) was also shown to affect HbA1c levels [32, 33]. The kappa coefficient values remained approximately the same after excluding persons with anemia, macrocytosis, microcytosis, and CKD stage 3 or greater. Using FPG alone, prediabetes was missed in $48.8 \%$ of our patients, while using FPG and HbA1c increased the detection rate to $74.4 \%$. Performing OGTT routinely might not be practical in clinical settings. However, a recent study demonstrated that random plasma glucose levels below a typical threshold of diabetes were predictive of diabetes development [34]. Such levels have not been explored in prediabetes but could potentially increase the detection rate.

From the multivariate analysis, hypertension and triglycerides $>150 \mathrm{mg} / \mathrm{dL}$ were factors significantly associated with prediabetes among HIV-infected individuals. These factors are recognized as risk factors for DM [21]. A recent study from China has shown that hypertension and prediabetes together increase the risk of cardiovascular disease [35]. Triglycerides $>150 \mathrm{mg} / \mathrm{dl}$, common in patients with uncontrolled DM, was another factor independently associated with prediabetes in the present study. A study in Bangladesh had previously demonstrated that high triglycerides were associated with prediabetes as well [36]. HCV infection was known to associate with insulin resistance and prediabetes [37]. In this study, positive anti-HCV showed borderline statistical significance. This might be due to the incomplete data on $\mathrm{HCV}$ coinfection.

The strength of our study was the detailed analysis of glycemia estimation using different methods. There were some limitations in the present study. As this was the cross-sectional study, we did not repeat the tests in the absence of unequivocal hyperglycemia according to the criteria for the diagnosis of diabetes recommended by the American Diabetes Association [21]. However, the guidelines suggest that for prediabetes testing, FPG, 2 h-PG, and $\mathrm{A} 1 \mathrm{C}$ are equally appropriate. We recruited only HIVinfected patients who received ART with an undetectable plasma viral load. Thus, the results from the present study might not be applicable to the ART-naïve HIVinfected population or HIV-infected patients without 
successful ART. Since the prevalence of prediabetes varies between different ethnic groups, the results may not be implied for non-Asian populations.

\section{Conclusions}

In summary, we observed the high prevalence of prediabetes among HIV-infected Thai patients receiving ART. The diagnosis methods of prediabetes have minimal to weak agreement. Using FPG together with $\mathrm{HbA1c}$ increased the detection rate to approximately $75 \%$ of prediabetes patients. Hypertension and triglycerides level over $150 \mathrm{mg} / \mathrm{dL}$ are factors significantly associated with prediabetes. HIV-infected patients that present with any of these factors should be assessed for prediabetes and progression to DM.

\section{Abbreviations}

2-h PG: 2-hour plasma glucose; ANOVA: Analysis of variance; ART: Antiretroviral therapy; BMI: Body mass index; Cl: Confidence interval; CKD: Chronic kidney disease; DM: Diabetes; eGFR: Estimated glomerular filtration rate; FPG: Fasting plasma glucose; Hb: Hemoglobin; HbA1c: Hemoglobin A1c; Hct: Hematocrit; HCV: Hepatitis C virus; HDL: High-density lipoprotein; HIV: Human immunodeficiency virus; LDL: Low-density lipoprotein; MCV: Mean corpuscular volume; NNRTI: Non-nucleoside reverse transcriptase inhibitor; OGTT: Oral glucose tolerance test; OR: Odds ratio; Pl: Protease inhibitor.

\section{Acknowledgements}

The authors would like to thank all patients for participating in this study.

\section{Author contributions}

Conceptualization: AP, HN, SR, SS. Data curation: SS. Methodology: HN, SR, SS. Formal analysis: AP, SS. Funding acquisition: SS. Investigations: SS. Project administration: SS. Writing —original draft: AP, SS. Writing — review and editing: AP, HN, SR, SS. All authors read and approved the final manuscript.

\section{Funding}

This study was supported by grants from the Faculty of Medicine Ramathibodi Hospital, Mahidol University and the Thailand Research Fund (RTA6080009).

\section{Availability of data and materials}

The datasets used and/or analyzed during the current study are available from the corresponding author on reasonable request.

\section{Ethics approval and consent to participate}

The study protocol was reviewed and approved by the Ethical Clearance Committee on Human Right Related to Research Involving Human Subjects of the Faculty of Medicine Ramathibodi Hospital, Mahidol University. Written informed consent was obtained from all participants.

\section{Consent for publication}

Not applicable.

\section{Competing interests}

The authors declare no conflict of interest for this article.

\section{Author details}

${ }^{1}$ Department of Medicine, Faculty of Medicine Ramathibodi Hospital, Mahidol University, Bangkok, Thailand. ${ }^{2}$ Division of Endocrinology, Diabetes and Metabolism, University of Illinois at Chicago, Chicago, IL, USA. ${ }^{3}$ Chakri Naruebodindra Medical Institute, Faculty of Medicine Ramathibodi Hospital, Mahidol University, 111 Moo 14, Bang Pla, Bang Phli, Samut Prakan 10540, Thailand.
Received: 16 November 2019 Accepted: 15 May 2020

Published online: 24 May 2020

\section{References}

1. Brown TT, Cole SR, Li X, Kingsley LA, Palella FJ, Riddler SA, et al. Antiretroviral therapy and the prevalence and incidence of diabetes mellitus in the multicenter AIDS cohort study. Arch Intern Med. 2005;165:1179-84.

2. Kalayjian RC, Machekano RN, Rizk N, Robbins GK, Gandhi RT, Rodriguez BA, et al. Pretreatment levels of soluble cellular receptors and interleukin- 6 are associated with HIV disease progression in subjects treated with highly active antiretroviral therapy. J Infect Dis. 2010;201:1796-805.

3. Neuhaus J, Jacobs DR Jr, Baker JV, Calmy A, Duprez D, La Rosa A, et al. Markers of inflammation, coagulation, and renal function are elevated in adults with HIV infection. J Infect Dis. 2010;201:1788-95.

4. Bourgi K, Wanjalla C, Koethe JR. Inflammation and metabolic complications in HIV. Curr HIV/AIDS Rep. 2018;15:371-81.

5. Betene ADC, De Wit S, Neuhaus J, Palfreeman A, Pepe R, Pankow JS, et al. Interleukin-6, high sensitivity C-reactive protein, and the development of type 2 diabetes among HIV-positive patients taking antiretroviral therapy. J Acquir Immune Defic Syndr. 2014;67:538-46.

6. Diabetes Prevention Program Research Group, Knowler WC, Fowler SE, Hamman RF, Christophi CA, Hoffman HJ, et al. 10-year follow-up of diabetes incidence and weight loss in the diabetes prevention program outcomes study. Lancet. 2009;374:1677-86.

7. Forouhi NG, Luan J, Hennings S, Wareham NJ. Incidence of Type 2 diabetes in England and its association with baseline impaired fasting glucose: the Ely study 1990-2000. Diabet Med. 2007;24:200-7.

8. Nathan DM, Davidson MB, DeFronzo RA, Heine RJ, Henry RR, Pratley R, et al. Impaired fasting glucose and impaired glucose tolerance: implications for care. Diabetes Care. 2007;30:753-9.

9. Barr EL, Zimmet PZ, Welborn TA, Jolley D, Magliano DJ, Dunstan DW, et al. Risk of cardiovascular and all-cause mortality in individuals with diabetes mellitus, impaired fasting glucose, and impaired glucose tolerance: the Australian Diabetes, Obesity, and Lifestyle Study (AusDiab). Circulation. 2007;116:151-7.

10. Emerging Risk Factors Collaboration, Sarwar N, Gao P, Seshasai SR, Gobin $R$, Kaptoge S, et al. Diabetes mellitus, fasting blood glucose concentration, and risk of vascular disease: a collaborative meta-analysis of 102 prospective studies. Lancet. 2010;375:2215-22.

11. Hoehner CM, Greenlund KJ, Rith-Najarian S, Casper ML, McClellan WM. Association of the insulin resistance syndrome and microalbuminuria among nondiabetic native Americans. The Inter-Tribal Heart Project. J Am Soc Nephrol. 2002;13:1626-34.

12. Melsom T, Mathisen UD, Ingebretsen OC, Jenssen TG, Njolstad I, Solbu $M D$, et al. Impaired fasting glucose is associated with renal hyperfiltration in the general population. Diabetes Care. 2011;34:1546-51.

13. Nguyen TT, Wang JJ, Wong TY. Retinal vascular changes in pre-diabetes and prehypertension: new findings and their research and clinical implications. Diabetes Care. 2007;30:2708-15.

14. Plantinga LC, Crews DC, Coresh J, Miller ER 3rd, Saran R, Yee J, et al. Prevalence of chronic kidney disease in US adults with undiagnosed diabetes or prediabetes. Clin J Am Soc Nephrol. 2010;5:673-82.

15. Dream Trial Investigators, Gerstein HC, Yusuf S, Bosch J, Pogue J, Sheridan $P$, et al. Effect of rosiglitazone on the frequency of diabetes in patients with impaired glucose tolerance or impaired fasting glucose: a randomised controlled trial. Lancet. 2006;368:1096-105.

16. Knowler WC, Barrett-Connor E, Fowler SE, Hamman RF, Lachin JM, Walker EA, et al. Reduction in the incidence of type 2 diabetes with lifestyle intervention or metformin. N Engl J Med. 2002;346:393-403.

17. Chantrathamachart P, Sungkanuparph S, Kiertiburanakul S, Malathum K. Diabetes mellitus and hypertension in HIV-infected patients receiving antiretroviral therapy: a pilot study. J Infect Dis Antimicrob Agent. 2006;23:131-8.

18. Kim PS, Woods C, Georgoff P, Crum D, Rosenberg A, Smith M, et al. A1C underestimates glycemia in HIV infection. Diabetes Care. 2009;32:1591-3.

19. Slama L, Palella FJ Jr, Abraham AG, Li X, Vigouroux C, Pialoux G, et al. Inaccuracy of haemoglobin A1c among HIV-infected men: effects of CD4 cell count, antiretroviral therapies and haematological parameters. J Antimicrob Chemother. 2014;69:3360-7. 
20. Hoffman R, Benz EJJ, Shatti SJ, Furie B. Hematology: basic principles and practice. New York: Churchill-Livingstone; 2004.

21. American Diabetes Association. 2. Classification and Diagnosis of Diabetes. Diabetes Care. 2017;40:S11-S24.

22. Aekplakorn W, Chariyalertsak S, Kessomboon P, Sangthong R, Inthawong R, Putwatana P, et al. Prevalence and management of diabetes and metabolic risk factors in Thai adults: the Thai National Health Examination Survey IV, 2009. Diabetes Care. 2011;34:1980-5.

23. Rhee JY, Bahtila TD, Palmer D, Tih PM, Aberg JA, LeRoith D, et al. Prediabetes and diabetes among HIV-infected adults in Cameroon. Diabetes Metab Res Rev. 2016;32:544-9.

24. Njuguna B, Kiplagat J, Bloomfield GS, Pastakia SD, Vedanthan R, Koethe $J R$. Prevalence, risk factors, and pathophysiology of dysglycemia among people living with HIV in sub-Saharan Africa. J Diabetes Res. 2018;2018:6916497.

25. Srivanich N, Ngarmukos C, Sungkanuparph S. Prevalence of and risk factors for pre-diabetes in HIV-1-infected patients in Bangkok, Thailand. J Int Assoc Physicians AIDS Care (Chic). 2010;9:358-61.

26. Camacho JE, Shah VO, Schrader R, Wong CS, Burge MR. Performance of A1c versus Ogtt for the diagnosis of prediabetes in a community-based screening. Endocr Pract. 2016;22:1288-95.

27. Pinelli NR, Jantz AS, Martin ET, Jaber LA. Sensitivity and specificity of glycated hemoglobin as a diagnostic test for diabetes and prediabetes in Arabs. J Clin Endocrinol Metab. 2011;96:E1680-3.

28. McHugh ML. Interrater reliability: the kappa statistic. Biochem Med (Zagreb). 2012;22:276-82.

29. Aekplakorn W, Tantayotai V, Numsangkul S, Sripho W, Tatsato N, Burapasiriwat $T$, et al. Detecting prediabetes and diabetes: agreement between fasting plasma glucose and oral glucose tolerance test in Thai adults. J Diabetes Res. 2015;2015:396505.

30. Coelho AR, Moreira FA, Santos AC, Silva-Pinto A, Sarmento A, Carvalho D, et al. Diabetes mellitus in HIV-infected patients: fasting glucose, A1C, or oral glucose tolerance test-which method to choose for the diagnosis? BMC Infect Dis. 2018;18:309.

31. Sakamoto N, Hu H, Nanri A, Mizoue T, Eguchi M, Kochi T, et al. Associations of anemia and hemoglobin with hemoglobin A1c among nondiabetic workers in Japan. J Diabetes Investig. 2019.

32. George C, Matsha TE, Korf M, Zemlin AE, Erasmus RT, Kengne AP. The agreement between fasting glucose and markers of chronic glycaemic exposure in individuals with and without chronic kidney disease: a crosssectional study. BMC Nephrol. 2020;21:32.

33. Jung M, Warren B, Grams M, Kwong YD, Shafi T, Coresh J, et al. Performance of non-traditional hyperglycemia biomarkers by chronic kidney disease status in older adults with diabetes: results from the Atherosclerosis Risk in Communities Study. J Diabetes. 2018;10:276-85.

34. Rhee MK, Ho YL, Raghavan S, Vassy JL, Cho K, Gagnon D, et al. Random plasma glucose predicts the diagnosis of diabetes. PLOS ONE. 2019;14:e0219964.

35. Liu HH, Cao YX, Li S, Guo YL, Zhu CG, Wu NQ, et al. Impacts of prediabetes mellitus alone or plus hypertension on the coronary severity and cardiovascular outcomes. Hypertension. 2018;71:1039-46.

36. Bhowmik B, Siddiquee T, Mujumder A, Afsana F, Ahmed T, Mdala IA et al. Serum lipid profile and its association with diabetes and prediabetes in a rural Bangladeshi population. Int J Environ Res Public Health. 2018;15:1944

37. Desouky DE, Kasemy Z, Abdel-Hamid AE, Omar MS. Insulin resistance and prediabetes in hepatitis C virus patients. Am J Med Sci. 2015;350:77-80.

\section{Publisher's Note}

Springer Nature remains neutral with regard to jurisdictional claims in published maps and institutional affiliations.
Ready to submit your research? Choose BMC and benefit from:

- fast, convenient online submission

- thorough peer review by experienced researchers in your field

- rapid publication on acceptance

- support for research data, including large and complex data types

- gold Open Access which fosters wider collaboration and increased citations

- maximum visibility for your research: over $100 \mathrm{M}$ website views per year

At BMC, research is always in progress.

Learn more biomedcentral.com/submissions 